\title{
A Novel Approach towards the Potential Effects of Chlorpyrifos on Testicular Biochemistry and Physiology of Male Sprague Dawely Rats
}

\author{
Muhammad Farrukh Tahir ${ }^{1}$, Shehbaz Ali', Muhammad Noman ${ }^{1}$, Moiffa Goher $^{3}$ \\ ${ }^{1}$ Department of Biochemistry, Molecular Biology Laboratory, Government College University, Faisalabad, 38000, Pakistan \\ ${ }^{2}$ Department of Biosciences and Technology, Khwaja Fareed University of Engineering and Information Technology, Rahim Yar Khan, Punjab, \\ Pakistan \\ ${ }^{3}$ Department of Chemistry, University of Agriculture, Faisalabad, Pakistan
}

DOI: $10.36348 /$ sjls.2020.v05i10.001 | Received: 19.09 .2020 | Accepted: 27.09 .2020 | Published: 03.10 .2020

*Corresponding author: Muhammad Noman

Abstract

Chlorpyrifos is among the commonly used pesticides used for self-harm. Chlorpyrifos is colorless crystal like solid with a strong odor. Pesticides like chlorpyrifos are necessarily poisonous but they play an important role in the availability of plenty of cheap and consistent supplies of food to the world population. The aims of this review article investigated the aspects to reduce the risk due to chlorpyrifos use among farmers and people by producing awareness. A decreased percentage of neutrophils in peripheral blood in animals poisoned with chlorpyrifos may suggest, neutrophils involves in phagocytosis during xenobiotic intoxication, during which some of the neutrophils might have ruptured. Chlorpyrifos modifies testicular capacities perhaps by acceptance of testicular oxidative pressure and hindrance of exercises of indicator catalysts, accordingly disturbing masculine generation. The outcome enemies of oxidants i.e SOD, CAT, G6PDH exercises in the hepatocytes, renal, spleen and cerebrum of rodents. The sub- deadly presentation of chlorpyrifos additionally cause decline in dimension of decreased GTH (glutathione) and ensuing increment in oxidized glutathione heights. So the outcome demonstrate that CPF presentation prompt oxidative worry in rodent tissues however the CPF introduction to rodents feed with oxidants vitamin $\mathrm{A}, \mathrm{E}$ and $\mathrm{C}$ for one month, averted unhinging of these enemy of oxidant limits. It also helpful to explain the mechanism that chlorpyrifos induce such changes in living organisms included humans.

Keywords: Chlorpyrifos, Biochemistry, Physiology, Pesticides, vitamins.

Copyright @ 2020: This is an open-access article distributed under the terms of the Creative Commons Attribution license which permits unrestricted use, distribution, and reproduction in any medium for non-commercial use (NonCommercial, or CC-BY-NC) provided the original author and source are credited.

\section{INTRODUCTION}

There are five major groups of pesticides used in Pakistan which are insect repellents, herbicides, wood preservatives fungicides, rodenticides and also insect killer insecticide. From these chemicals used on crops, chlorpyrifos is most commonly used pesticide. Chlorpyrifos, CPF (0,0-diethyl-0-3,5,6-trichloro-2pyridyl phosphorothioate), sold under many brand names Dursban, Lorsban, and Renobamn, is an organophosphate pesticide use to execute bugs including creepy crawlies and worm. It is utilized on harvests, creatures and structures. It was presented in 1965 by Dow substance organization. It follows up on sensory system of creepy crawlies by hindering acetylcholinesterase [1].

Its exposure during pregnancy may harm the mental development of children, because of these conditions most home use was banned in 2001 in the
U.S. In agriculture, it is most commonly used insecticide" in United States, and before its ban for residential use it was one of the most commonly used insecticides. Relatively mild poisoning of CPF can result in eye watering, increased saliva and sweating, nausea and headache. Intermediate exposure may lead to muscle spasms or weakness, vomiting or diarrhea and impaired vision. Symptoms of severe poisoning include seizures, unconsciousness, paralysis, and suffocation from lung failure [2].

Chlorpyrifos is among the commonly used pesticides used for self-harm. Chlorpyrifos is colorless crystal like solid with a strong odor. Among 50 farm pesticides studied, chlorpyrifos was one of two found to be associated with higher risks of lung cancer among frequent pesticide applicators than among infrequent or nonusers. For acute effects the WHO classifies chlorpyrifos as class 2nd moderately hazardous. The oral $\mathrm{LD}_{50}$ for chlorpyrifos in experimental animals is 32 
to $1000 \mathrm{mg} / \mathrm{kg}$. The dermal $\mathrm{LD}_{50}$ in rats is greater then $2000 \mathrm{mg} / \mathrm{kg}$ and thousand to $2000 \mathrm{mg} / \mathrm{kg}$ in rabbits. The 4 hour inhalation $\mathrm{LC}_{50}$ for chlorpyrifos in rats is grater then $2000 \mathrm{mg} / \mathrm{m} 3[3]$.

Over use of pesticides has resulted in serious problem to man and the environment. And over $98 \%$ of sprayed insecticides and $95 \%$ of herbicides reach a destination other then their target species. In addition, the use of pesticides reduced biodiversity and nitrogen fixation and destroys habitat of birds and other animals. The high levels of the indicators found in the urine of rural and urban residents show that in the city of Lahore, dust dispersing from industrial sites and farms are major contributors in human insecticide exposure in addition to pesticides found on food [4].

Pakistan is the second biggest consumer of pesticides in South Asia and its use is rising. Globally around 200,000 people die each year in the developing world due to organophosphorus pesticide poisoning. Pesticides contaminated dust exposure, risk diagnosis and exposure markers in occupational and residential settings of Lahore, Pakistan' by the journal "Environmental Toxicology" and "Pharmacology". Some other researchers also says that pesticides like chlorpyrifos are necessarily poisonous but they play an important role in the availability of plenty of cheap and consistent supplies of food to the world population [5].

While DDT is banned in many countries and some affected bird populations are now beginning to recover, hundreds of birds species and also human beings continue to be threatened by other pesticides. Also a number of accidents occurred during transfer of pesticides to smaller containers, handling and storage of left-over toxicants [6].

The aims of this review article investigated aspects to reduce the risk due to chlorpyrifos use among farmers and people by producing awareness. The danger of using the chlorpyrifos persists either it is used in high amount or in low amount so it must be used when it is needed. The study further needed to investigate the biochemistry as well as medical physiology of the testes to understand the nature of cells using in laboratory for research [7].

\section{Approach to Hematological and Histological Parameters}

The decrease in RBC count, $\mathrm{Hb}$ and PCV could be described are retarded as haemopoisis, destruction and shrinkage of RBC. MCV, MCH and MCHC showed significant decrease in all doses in the present investigation, due to destruction of RBC (size and shape) and decrease in $\mathrm{Hb}$ synthesis and hemoglobin content. These symptoms imply the microcytic- hypo chromic anemia. A decreased percentage of neutrophils in peripheral blood observed in animals poisoned with chlorpyrifos may suggest, neutrophils involves in phagocytosis during xenobiotic intoxication, during which some of the neutrophils might have ruptured [8].

Chlorpyrifos cause huge increments in RBC'S delicacy and malondialdehyde fixation, which were ameliorative via pre-treatment with nutrient $\mathrm{C}$ taking everything into account, the investigation demonstrated that CPF evoked erythrocyte delicacy because of expanded lipid peroxidative changes was ameliorative by pretreatment with nutrient $\mathrm{C}[9]$.

Chlorpyrifos medications $(\mathrm{K}, \mathrm{W}$ and $\mathrm{H})$
modify uniquely the testicular phospholipid peroxidation stages, while, the decrease in the complete GT (glutathione) was happened just in (W and $\mathrm{H}$ ) gatherings, in contrasting and control gathering. Additionally, there was critical reduction in the exercises of basic and corrosive P \& L (phosphatase and lactate dehydrogenase) in every single treated gathering. All out protein level showed a height in testicular matter in examination with the control gathering. Handling- subordinate histopathological variations were seen in testicles of chlorpyrifos-W amass as it were. So Chlorpyrifos modifies testicular capacities perhaps by acceptance of testicular oxidative pressure and hindrance of exercises of indicator catalysts, accordingly disturbing masculine generation [10].

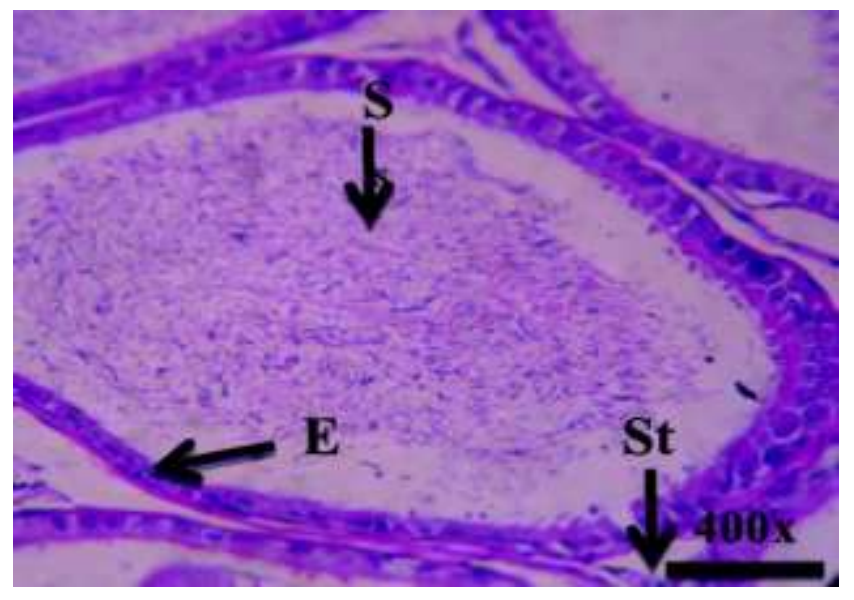


Fig-1: Histological changes on Testicular of Male Sprague Dawely Rats

So CPF administrated orally to rodents separately with 5 dosages for each week for twenty eight days. 24 hours later the last action the rodents were relinquished utilizing soporific ether [29, 30]. Testicles collected, prepared and gauged. Right testicles homogenate was acquired by centrifugation, LPO (lipid peroxidation), complete GTH (glutathione), exercises of basic then corrosive phosphatases, LDH (lactate dehydrogenase) and absolute protein were estimated. Also, for the left testis outcome was that testicles loads were essentially diminished in (W) assemble [11].

Creatures presented to high dose $(9 \mathrm{mg} / \mathrm{kg} / \mathrm{day})$ showed indications of harmfulness including piloerection, looseness of the bowels, nose and eyes dying, diminished body weight and passing of animals. There is an expansion in adrenal weight and abatement in the heaviness of testicles in the creatures of high dose $(9 \mathrm{mg} / \mathrm{kg} / \mathrm{day})$. A portion subordinate inhabitation of acetylcholinesterase (AChE) movement in RBCs (22$60 \%$ ) and brain $(7-52 \%)$ was watched. Minuscule examination of various tissues of male rodents demonstrated minor histopathological changes in cerebrum, liver, testicles, epididymis and adrenal [28, 29]. The action of testicular catalysts SDH, G6PDH and testicular substance of sialic corrosive and cholesterol were discovered expanded in creatures of high dose $(9 \mathrm{mg} / \mathrm{kg} /$ day). There was decline in RBCs check and dimensions of hemoglobin $(\mathrm{Hb})$ and hematocrit (Hct) with increment in WBCs tallies. While, absolute protein was diminishes altogether at all the portion level in testis and epididymis, glucose level demonstrated a noteworthy reduction at high portion [12].

A portion subordinate increment was seen in the dimension of serum triglycerides. There was no adjustment in the sperm motility and sperm morphology at any portion level aside from a decline in the sperm counts $(114.1 * 10 \mathrm{~g}$ in high portion for gathering against $158.9 * 10 \mathrm{~g} /$ day control) it is recommended that $\mathrm{CPF}$ at 9 $\mathrm{mg} / \mathrm{kg} /$ day portion for 90 days has caused toxicological change alongside gentle testicular and spermatotoxic impact in male rodents. The body weight of creatures did not demonstrate any critical alteration, in any case, a noteworthy decrease was seen in testicles, from the aftereffect of these examinations it is presumed that $\mathrm{CPF}$ instigated separate testicular harm and result in decrease in sperm check and in this manner influence richness. Little variations in sperm checks are presently to have antagonistic impact on humanoid ripeness. Along these lines, utilization of such bug spray ought to be constrained to a structured program [13].

\section{Approach to Biochemical Parameters}

The outcome enemies of oxidants i.e SOD, CAT, G6PDH exercises in the hepatocytes, renal, spleen and cerebrum of rodents. The sub- deadly presentation of chlorpyrifos additionally cause decline in dimension of decreased GTH (glutathione) and ensuing increment in oxidized glutathione heights. So the outcome demonstrate that $\mathrm{CPF}$ presentation prompt oxidative worry in rodent tissues however the $\mathrm{CPF}$ introduction to rodents feed with oxidants vitamin A,E and $\mathrm{C}$ for one month, averted unhinging of these enemy of oxidant limits[25]. The amassing of thiobarbituric corrosive responsive substances were additionally not found in the tissue of rodents feed with enemies of oxidants nutrients on $\mathrm{CPF}$ presentation. Throb movement, which is touchy to OP pestisides, was not noteworthy occupied in these rodents so this demonstrates oral admission of nutrients A,E and C keeps the oxidative worry in rodents; produce by CPF. Was that due to CPF there is a rise in the dimension of thiobarbituric corrosive responsive substances (TBARS) and hindrance of acetylcholinesterase (AChE) [14].

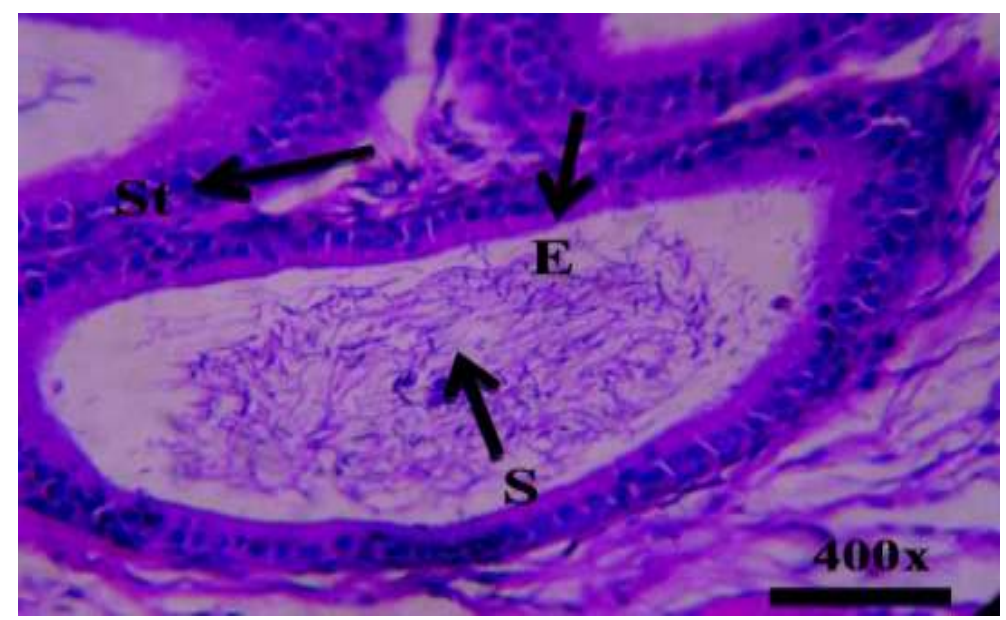

Fig-2: Biochemical changes on Testicular of Male Sprague Dawely Rats

Fetolethal impacts were not seen at tried portion stages as confirm by number of insertions, and live embryos/dam, however critical adjustments were noted in percent $\delta$ resorption. There were no real contortions, yet some slight irregularities, for example, diminished parietal solidification and nonattendance of 
groups found critical in high portion were not measured as compound-linked impacts [25-27]. Then again the aggregation of chlorpyrifos buildup in dams was more in cerebrum than in liver. The dimension of buildup in babies was in the accompanying request: liver $>$ mind $>$ placenta > amniotic liquid. Despite the fact that, the complete buildup was higher in embryos than in dams, the nonattendance of variations from the norm in fetal uncivilized morphology, instinctive and skeleton recommend that specialized $\mathrm{CPF}$ at tried portion stages is non-teratogenic in rodents [14-16].

Grown-up long-evans male rodents where kept up at $350 \mathrm{~g}$ body weight by constrained access to a chlorpyrifos containing diet to create an admission of $0,1,5 \mathrm{mg} / \mathrm{kg} /$ day chlorpyrifos. The result was that when the rodents were tried in a morris water labyrinth [1719]. There were some intellectual shortages watched. A steady finding in the water labyrinth was one of the adjusted swimming example or hunt system [20]. The high portion feed bunches indicated progressively propensity to swim in the external annulus or to swim near the dividers of the tank [21-23]. Over all dietary presentation to $\mathrm{CPF}$ created enduring neurobehavioral reaction to intense difficulties [24].

\section{CONCLUSION}

This review article investigation the current advancements for the effects of chlorpyrifos on testicular biochemistry and physiology of male sprague dawely rats. Biochemical and physiological changes occurs when higher dose of the chlorpyrifos given to specific experimental animal. It also helpful to explain the mechanism that chlorpyrifos induce such changes in living organisms included humans.

\section{REFERENCES}

1. Akhtar, N., Srivastava, M. K., \& Raizada, R. B. (2009). Assessment of chlorpyrifos toxicity on certain organs in rat, Rattus norvegicus. $J$ Environ Biol, 30(6), 1047-1053.

2. Albasher, G., Almeer, R., Al-Otibi, F. O., AlKubaisi, N., \& Mahmoud, A. M. (2019). Ameliorative effect of Beta vulgaris root extract on chlorpyrifos-induced oxidative stress, inflammation and liver injury in rats. Biomolecules, 9(7), 261.

3. Ahmadian, E., Khosroushahi, A. Y., Eghbal, M. A., \& Eftekhari, A. (2018). Betanin reduces organophosphate induced cytotoxicity in primary hepatocyte via an anti-oxidative and mitochondrial dependent pathway. Pesticide biochemistry and physiology, 144, 71-78.

4. Tanvir, E. M., Afroz, R., Chowdhury, M. A. Z., Khalil, M. I., Hossain, M. S., Rahman, M. A., \& Gan, S. H. (2015). Honey has a protective effect against chlorpyrifos-induced toxicity on lipid peroxidation, diagnostic markers and hepatic histoarchitecture. European Journal of Integrative Medicine, 7(5), 525-533.
5. Fernández, M., Bourguignon, N., Lux-Lantos, V., \& Libertun, C. (2010). Neonatal exposure to bisphenol and reproductive and endocrine alterations resembling the polycystic ovarian syndrome in adult rats. Environmental health perspectives, 118(9), 1217-1222.

6. Rhodes, M. C., Seidler, F. J., Qiao, D., Tate, C. A., Cousins, M. M., \& Slotkin, T. A. (2004). Does pharmacotherapy for preterm labor sensitize the developing brain to environmental neurotoxicants? Cellular and synaptic effects of sequential exposure to terbutaline and chlorpyrifos in neonatal rats. Toxicology and applied pharmacology, 195(2), 203-217.

7. Viswanath, G., Chatterjee, S., Dabral, S., Nanguneri, S. R., Divya, G., \& Roy, P. (2010). Anti-androgenic endocrine disrupting activities of chlorpyrifos and piperophos. The Journal of steroid biochemistry and molecular biology, 120(1), 22-29.

8. Maranghi, F., \& Mantovani, A. (2012). Targeted toxicological testing to investigate the role of endocrine disrupters in puberty disorders. Reproductive Toxicology,33(3), 290 296.

9. Bollard, M. E., Stanley, E. G., Lindon, J. C., Nicholson, J. K., \& Holmes, E. (2005). NMRbased metabonomic approaches for evaluating physiological influences on biofluid composition. NMR in Biomedicine: An International Journal Devoted to the Development and Application of Magnetic Resonance In vivo, 18(3), 143-162.

10. Jahan, S., Azad, T., Ayub, A., Ullah, A., Afsar, T., Almajwal, A., \& Razak, S. (2019). Ameliorating potency of Chenopodium album Lin and vitamin C against mercuric chloride-induced oxidative stress in testes of Sprague Dawley rats. Environmental health and preventive medicine, 24(1), 62.

11. El-Demerdash, F. M., Jebur, A. B., \& Nasr, H. M. (2013). Oxidative stress and biochemical perturbations induced by insecticides mixture in rat testes. Journal of Environmental Science and Health, Part B, 48(7), 593-599.

12. Baykalir, B. G., Seven, P. T., Gur, S., \& Seven, I. (2018). The effects of propolis on sperm quality, reproductive organs and testicular antioxidant status of male rats treated with cyclosporineA. Animal Reproduction (AR), 13(2), 105-111.

13. Mansour, S. A., Abbassy, M. A., \& Shaldam, H. A. (2017). Zinc ameliorates oxidative stress and hormonal disturbance induced by methomyl, abamectin, and their mixture in male rats. Toxics, 5(4), 37.

14. Mansour, S. A., Abbassy, M. A., \& Shaldam, H. A. (2017). Zinc ameliorate oxidative stress and hormonal disturbance induced by methomyl, abamectin, and their mixture in male rats. Toxics, 5(4), 37.

15. Roy, D. N., Goswami, R., \& Pal, A. (2017). The insect repellents: A silent environmental chemical 
toxicant to the health. Environmental toxicology and pharmacology, 50, 91-102.

16. Naeem, M., Ali, J., Hassan, M. Z., Arshad, B., Rao, M. H. I., Sarmad, M. S. K., \& amp; Hassan, M. U. (2019). Novel Approach towards DNA Barcoding as a Tool in Molecular Biology and Biological Activities of Cyclotides with Particular Emphasizes at Molecular Level. Biological Forum-An International Journal, 11(2): 83-96.

17. Naeem, A., Saddique, S., \&amp; Chand, S. A. (2019). Advancement and Future Directions towards Herbal Treatment for Various Diseases.

18. Das, U. B., Mallick, M., Debnath, J. M., \& Ghosh, D. (2002). Protective effect of ascorbic acid on cyclophosphamide-induced testicular gametogenic and androgenic disorders in male rats. Asian journal of andrology, 4(3), 201-208.

19. Naeem, M., Hayat, M., Azmi, U. R., Ahmed, S., \&amp; Irfan, M. (2019). Molecular Identification of Ten Palm Species using DNA Fingerprinting. Int. J. Pure App. Biosci, 7(1), 46- 51.

20. Ahmad, I., Khan, S., Naeem, M., Hayat, M., Azmi, U. R., Ahmed, S., \& Irfan, M. (2019). Molecular Identification of Ten Palm Species using DNA Fingerprinting. Int. J. Pure App. Biosci, 7(1), 46-51. 14.

21. Naeem, M., Hayat, M., Qamar, S. A., Mehmood, T., Munir, A., Ahmad, G., \& Hussain, A. (2019). Risk factors, genetic mutations and prevention of breast cancer. Int. J. Biosci, 14(4), 492-496.

22. Shafiq, S., Adeel, M., Raza, H., Iqbal, R., Ahmad, Z., Naeem, M., \& Azmaai, U. R. (2019). Effects of Foliar Application of Selenium in Maize (Zea Mays L.) under Cadmium Toxicity. In Biological Forum-An International Journal 11(2): 27-37.

23. Usman, G., Muhammad, N., Hamza, R., Usman, I., Ayesha, A., Saqib, U., \& Fatima, Q. (2019). A Novel Approach towards Nutraceuticals and
Biomedical Applications. Scholars International Journal of Biochemistry, 2(10), 245-252.

24. Uzun, F. G., Kalender, S., Durak, D., Demir, F., \& Kalender, Y. (2009). Malathion-induced testicular toxicity in male rats and the protective effect of vitamins $\mathrm{C}$ and E. Food and chemical toxicology, 47(8), 1903-1908.

25. Naeem, M., Ashraf, A., Safdar, H. M. Z., Khan, M. Q., Rehman, S. U., Iqbal, R., ... \& Ahmad, G. Biochemical changes in patients with chronic kidney failure in relation to complete blood count and anemia.

26. Ghani, U., Naeem, M., Bukhari, S. S. H., Yar, G., Tariq, I., Siddique, S., ... \& Bukhari, S. A. H. Prevalence and Risk Factors Associated with Hepatitis B and Hepatitis C and their Correlation with Inflammatory Markers among Southern Region of Punjab. Biological Forum - An International Journal, 11(2): 136-143.

27. Salian, S., Doshi, T., \& Vanage, G. (2009). Neonatal exposure of male rats to Bisphenol A impairs fertility and expression of sertoli cell junctional proteins in the testis. Toxicology, 265(12), 56-67.

28. Payne, A. H., Kelch, R. P., Murono, E. P., \& Kerlan, J. T. (1977). Hypothalamic, pituitary and testicular function during sexual maturation of the male rat. Journal of Endocrinology, 72(1), 17-26.

29. Payne, A. H., Kelch, R. P., Murono, E. P., \& Kerlan, J. T. (1977). Hypothalamic, pituitary and testicular function during sexual maturation of the male rat. Journal of Endocrinology, 72(1), 17-26.

30. International, C. O. Z. N. (2012). Amendment of Articles 8, 9, 10, 21 and 78 of the International Code of Zoological Nomenclature to expand and refine methods of publication. ZooKeys, (219):200209. 